\title{
Improvement in electrical, thermal and mechanical properties of epoxy by filling carbon nanotube
}

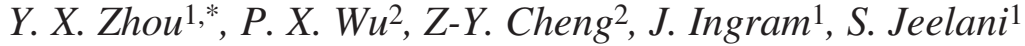 \\ ${ }^{1}$ Tuskegee University's Center for Advanced Materials (T-CAM), Tuskegee, AL 36088, USA \\ ${ }^{2}$ Materials Research and Education Center, Auburn University, Auburn, AL 36849, USA
}

Received 22 September 2007; accepted in revised form 7 November 2007

\begin{abstract}
In this study, electrical, thermal and mechanical properties of multi-walled carbon nanotubes (CNTs) reinforced Epon 862 epoxy have been evaluated. Firstly, 0.1, 0.2, 0.3, and $0.4 \mathrm{wt} \% \mathrm{CNT}$ were infused into epoxy through a high intensity ultrasonic liquid processor and then mixed with EpiCure curing agent $W$ using a high speed mechanical agitator. Electric conductivity, dynamic mechanical analysis (DMA), three point bending tests and fracture tests were then performed on unfilled, CNT-filled epoxy to identify the loading effect on the properties of materials. Experimental results show significant improvement in electric conductivity. The resistivity of epoxy decreased from $10^{14} \Omega \cdot \mathrm{m}$ of neat epoxy to $10 \Omega \cdot \mathrm{m}$ with $0.4 \% \mathrm{CNT}$. The experimental results also indicate that the frequency dependent behavior of CNT/epoxy nanocomposite can be modeled by $R-C$ circuit, permittivity of material increase with increasing of CNT content. DMA studies revealed that filling the carbon nanotube into epoxy can produce a $90 \%$ enhancement in storage modulus and a $17^{\circ} \mathrm{C}$ increase in $T_{g}$. Mechanical test results showed that modulus increased with higher CNT loading percentages, but the 0.3 wt $\%$ CNT-infusion system showed the maximum strength and fracture toughness enhancement. The decrease in strength and fracture toughness in $0.4 \% \mathrm{CNT} / \mathrm{epoxy}$ was attributed to poor dispersions of nanotubes in the composite.
\end{abstract}

Keywords: nanocomposites, carbon nanotubes, epoxy resin, electric-thermal-mechanical properties

\section{Introduction}

Epoxy resin is the polymer matrix used most often with reinforcing fibers for advanced composites applications. The resins of this class have good stiffness, specific strength, dimensional stability, and chemical resistance, and show considerable adhesion to the embedded fiber. Over the years, many attempts have been made to modify epoxy by adding either rubber particles [1-2] or fillers [3-4] to improve the matrix-dominated composite properties. The addition of rubber particles improves the fracture toughness of epoxy, but decreases its modulus and strength. The addition of fillers, on the other hand, improves the modulus and strength of epoxy, but decreases its fracture toughness. The heat deflection temperature of epoxy is also improved by the addition of fillers. In recent years, nanosized fillers such as nanoparticles, nanotubes, clay and nanofibers have been considered as filler material for epoxy to produce high performance composites with enhanced properties [5-10].

Carbon nanotubes are excellent candidates for multi-functional nano-reinforcing a variety of polymer matrices because of their high strength $(\sim 100$ times stronger than steel) and modulus (about $1 \mathrm{TPa}$ ), high thermal conductivity (about twice as high as diamond), excellent electrical capacity (1000 times higher than copper), and thermal stability $\left(2800^{\circ} \mathrm{C}\right.$ in vacuum) [11]. Nanophased matrices based on polymers and carbon nanotubes have 
attracted great interest because they frequently include superior mechanical, electronic, and flameretardant properties. Different polymer/CNT nanocomposites have been synthesized by incorporating CNTs into various polymer matrices, such as polyamides [12], polyimides [13-15], epoxy [16], polyurethane $[17,18]$ and polypropylene [19-21]. Previous results indicated that the addition of small amounts of CNT $(<1 \mathrm{wt} \%)$ to a matrix system can increase electric, thermal and mechanical properties without compromising the weight or processability of the composite. These polymer-based nanocomposites derive their high properties, particularly mechanical properties, at low filler volume fractions owing to the high aspect ratio and high surface area to volume ratio of the nano-sized particles. According to Reynaud et al. [22], an interface of $1 \mathrm{~nm}$ thick represents roughly $0.3 \%$ of the total volume of polymer in case of micro particle filled composites, whereas it can reach $30 \%$ of the total volume in case of nanocomposites. However, high specific surface area causes strong tendency to agglomerate, which reduces the strength of nanocomposite by stress concentration effect. When dispersing conductive CNT in polymer matrix, it is important to keep the filler volume (or weight) fraction below a certain value to maintain the strength and fracture toughness. Optimal loading of CNT in matrix is key parameter to develop multi-functional nanophased composite.

The purpose of this paper is to show the effect of carbon nanotubes loading on the electronic, thermal and mechanical properties of epoxy. An ultrasonicator was used to process the CNT-epoxy nanocomposite. Dynamic Mechanical Analysis (DMA) was performed to evaluate thermal performances. Flexural tests and fracture test were performed to evaluate mechanical performances. Microscopic

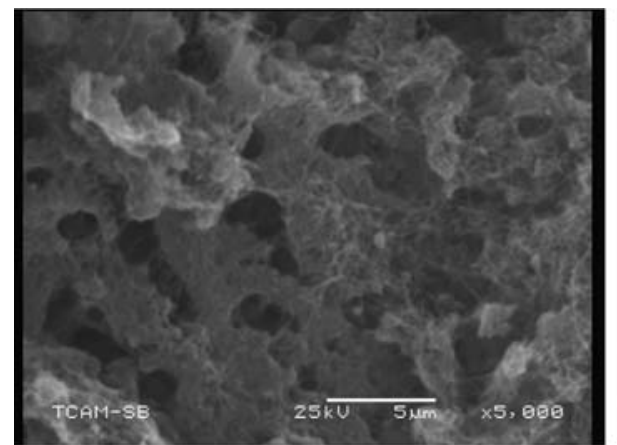

a) approaches were used to investigate the dispersion of CNT and material's failure mechanisms.

\section{Material processing}

The epoxy used was Part A: Epon 862 (bisphenol F epoxy) and Part B: EpiCure curing agent $W$, both purchased from Miller-Stephenson Chemical Company, Inc. Carbon Nanotechnologies, Inc. produced the multi-walled carbon nanotubes (purity $>95 \%$ ) used in this study. The tube diameter ranges from 30 to $50 \mathrm{~nm}$, the tube length ranges from 3 to $\mu \mathrm{m}$. The weight fraction of the carbon nanotubes ranged from 0 to $0.4 \mathrm{wt} \%$, to help identify the loading with the best thermal and mechanical properties.

Figure 1 shows the pictures of received carbon nanotubes at different magnifications. High specific surface area and cotton-like entanglements caused the formation of agglomerates [16]. Agglomerates of CNTs, called nanoropes, are difficult to separate and infiltrate with the matrix. For polymer matrix nanocomposites, high power dispersion methods, such as ultrasound and high-speed shearing, are the simplest and most convenient to improve the dispersion of nanosized fillers in a polymer matrix $[15,16]$. In this study, the components were mixed using a high-intensity ultrasonic processor. In this case, the application of alternating acoustic pressure above the cavitation threshold creates numerous cavities in the liquid. Some of these cavities oscillate at a frequency of the applied field (usually $20 \mathrm{kHz}$ ) whereas the gas content inside these cavities remains constant. However, some other cavities grow intensely under tensile stresses whereas yet another portion of these cavities that are not completely filled with gas start to collapse under the compression stresses of the sound wave. In the latter case, the collapsing cavity generates tiny par-

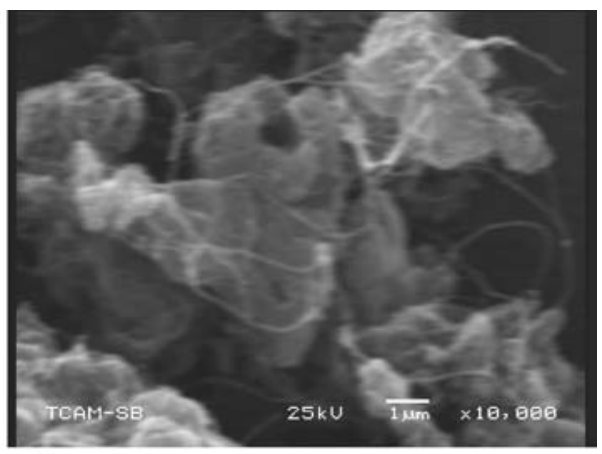

b)

Figure 1. SEM pictures of as received carbon nanotube at different magnification 
ticles of debris and the energy of the collapsed one is transformed into pressure pulses. It is noteworthy that the formation of the debris further facilitates the development of cavitation. It is assumed that acoustic cavitation in liquids develops according to a chain reaction. Therefore, individual cavities on real nuclei develop so rapidly that within a few microseconds an active cavitation region is created close to the source of the ultrasound probe. The development of cavitation processes in the ultrasonically processed melt creates favorable conditions for the intensification of various physicochemical processes. Acoustic cavitation accelerates heat and mass transfer processes such as diffusion, wetting, dissolution, dispersion, and emulsification. The uniform dispersion of CNF was observed in sonication process [8].

Pre-calculated amounts of carbon nanotubes and Epon 862 resin were carefully weighed and mixed together in a beaker. A high-intensity, ultrasonic irradiation mixed the CNTs and resin for an hour on pulse mode, $50 \mathrm{sec}$ on/25 sec off (Ti-horn, $20 \mathrm{kHz}$ Sonics Vibra Cell, Sonics \& Materials, Inc). The beaker containing the mixture was submerged in an ice bath to keep it cool during the sonication process. Once the irradiation was complete, EpiCure curing agent $W$ was added to the modified resin and mixed using a high-speed mechanical stirrer for about 10 minutes. The mix ratio of Epon 862 and $W$ agent was 100:26. The mixing of epoxy and curing agent initially produced highly reactive, volatile vapor bubbles, which could create voids and detrimentally affect the properties of the final product. To reduce the chance of voids, the liquid was preheated to $80^{\circ} \mathrm{C}$ to reduce its viscosity and a high vacuum system was used for about 30 minutes. After the bubbles were completely removed, the mixture was transferred to plasticand Teflon-coated metal rectangular molds and cured for 4 hours at $120^{\circ} \mathrm{C}$. The cured material was then trimmed. Finally, test samples were machined for thermal and mechanical characterization and all panels were post-cured at $170^{\circ} \mathrm{C}$ for 4 hours in a Lindberg/Blue Mechanical Convection Oven.

\section{Experimental results and discussions}

\subsection{Electric properties}

The electrical properties of the neat and nanophased epoxy were measured by using an Agilent 4294-A Precision Impedance analyzer. The composites were cut into rectangular bars with dimension of $8 \mathrm{~mm} \times 4 \mathrm{~mm} \times 1 \mathrm{~mm}$ (length, width and thickness) by a diamond saw. The two end surfaces were fully coated with gold as electrodes, which is about $4 \mathrm{~mm}^{2}$. The measurement was carried at frequencies from $100 \mathrm{~Hz}$ to $10 \mathrm{MHz}$ at room temperature. In the measurement, the impedance of the sample at each frequency was measured and recorded. The resistivity of the composites was calculated using the measured impedance and the geometry of the sample.

The application of conductive nano-particles to an insulating polymer matrix is supposed to induce an electrical conductivity, when the volume fraction exceeds the percolation threshold [23]. Generally, the percolation threshold is considered to be lower for fiber-shaped fillers (high aspect ratio) than for spherical particles. The results shown in Figure 2 are the resistivity of the neat and nanophased epoxy at frequency $100 \mathrm{~Hz}$. In this figure, the impedance results of each material are consistent, even some samples are not very uniform. A dramatic decrease in resistivity has been found in nanophased epoxy. With only $0.2 \%$ CNT, resistivity of epoxy decreased from $10^{14} \Omega \cdot \mathrm{m}$ of neat epoxy to $10 \Omega \cdot \mathrm{m}$.

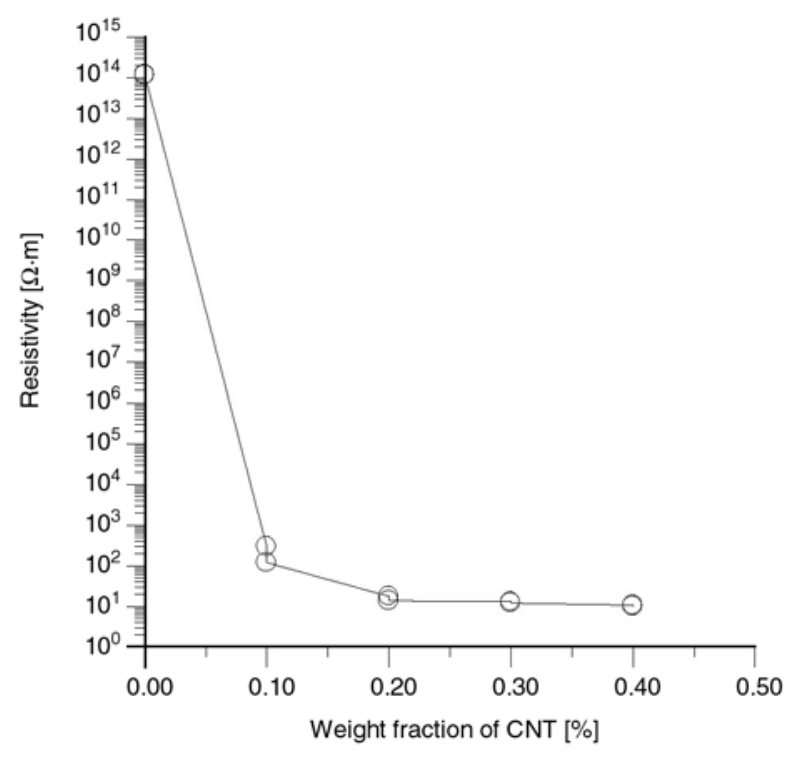

Figure 2. Effect of CNT weight fraction on resistivity of epoxy 
According to Gojny's results [23, 24], a reagglomeration of nanotubes will lead to conductive paths at lower filler contents, depending on the aspect ratio and the mobility in the matrix. The CNTs have the highest tendency to re-agglomerate under formation of conductive paths. The percolation threshold has, therefore, been determined to be below $0.1 \mathrm{wt} \%$. However, once CNT loading is higher that $0.2 \%$, resistivity decreased with CNT content slowly.

Figure 3 shows the effect of frequency on resistivity of nanophased epoxy. It is interesting that the impedance of the sample decreases significantly with frequency at frequencies higher than $100 \mathrm{kHz}$, indicating that at high frequency the impedance of the sample is dominated by the capacitance of the epoxy matrix. Therefore, it is possible to determine the connectivity between the CNT and polymer matrix by using the complex resistivity of the sample at different frequencies over a broad frequency range.

From Figure 3, the frequency dependent behavior of CNT/epoxy sample can be simulated by using $R$ - $C$ circuit. For $R-C$ circuit, the impedance is given by the Equation (1):

$$
Z=\frac{R}{\sqrt{1+(2 \pi f)^{2} R^{2} C^{2}}}
$$

where $R$ is resistance, $C$ is the capacitor's capacitance and $f$ is frequency. The resistance and capacitance of rectangular bars are given by Equations (2) and (3):

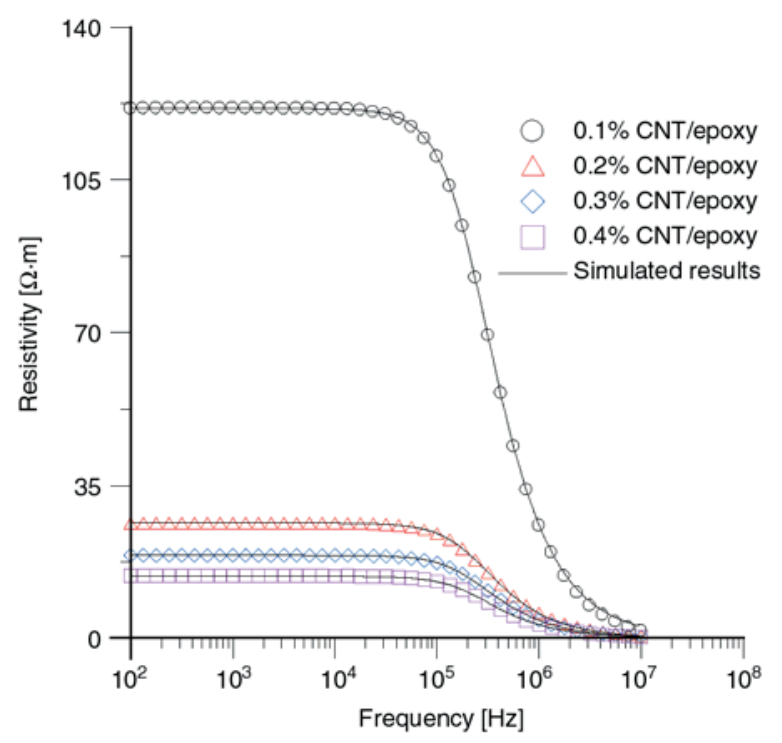

Figure 3. Resistivity vs. frequency for the composites with different concentrations

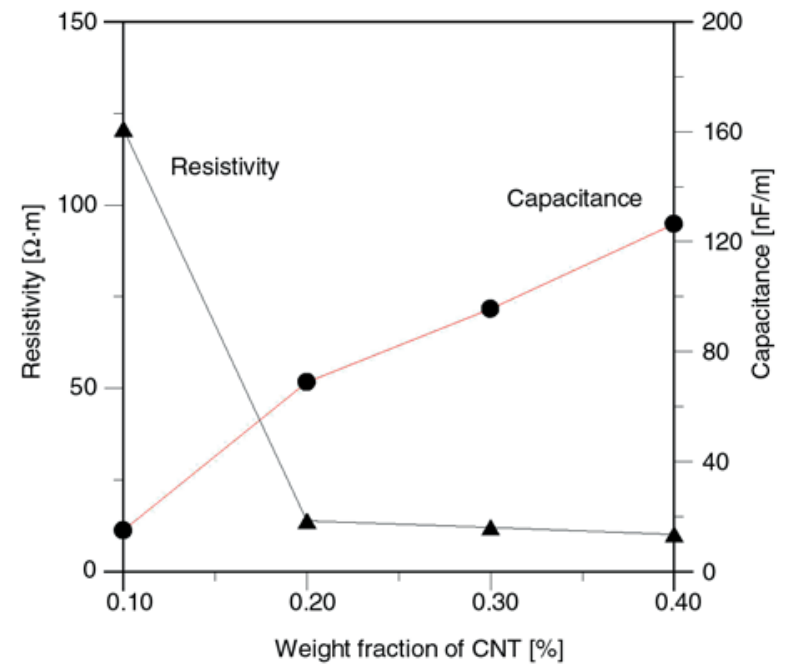

Figure 4. Effect of CNT content on electric parameters

$$
\begin{aligned}
R & =\frac{\rho L}{W T} \\
C & =\frac{\varepsilon W T}{L}
\end{aligned}
$$

where $\varepsilon$ is the permittivity of the dielectric and $\rho$ is the resistivity. Both of them are material parameters. $L, W$ and $T$ are length, width and thickness of sample, respectively. Substituting Equations (2) and (3) into Equation (1) and rearranging, one can obtain the Equation (4):

$\rho^{*}=\frac{\rho}{\sqrt{1-(2 \pi f)^{2} \rho^{2} \varepsilon^{2}}}$

where $\rho^{*}$ is resistivity of the composites calculated by using the measured impedance and the geometry of the sample. From experimental results and Equation (4), resistivities and permittivities of nanophased epoxy were simulated and plot them as function of CNT content (Figure 4). As we expected, resistivity descreased, and permittivity increased with increasing of CNT. The solid lines in Figure 3 shows simulated results, which agree with experimental data well.

\subsection{Thermal properties}

Dynamic Mechanic Analysis (DMA) was performed on a TA Instruments 2980, operating in the three-point bending mode at an oscillation frequency of $1 \mathrm{~Hz}$. Data were collected from room temperature to $200^{\circ} \mathrm{C}$ at a scanning rate of $10^{\circ} \mathrm{C} / \mathrm{min}$. The sample specimens were cut into rec- 


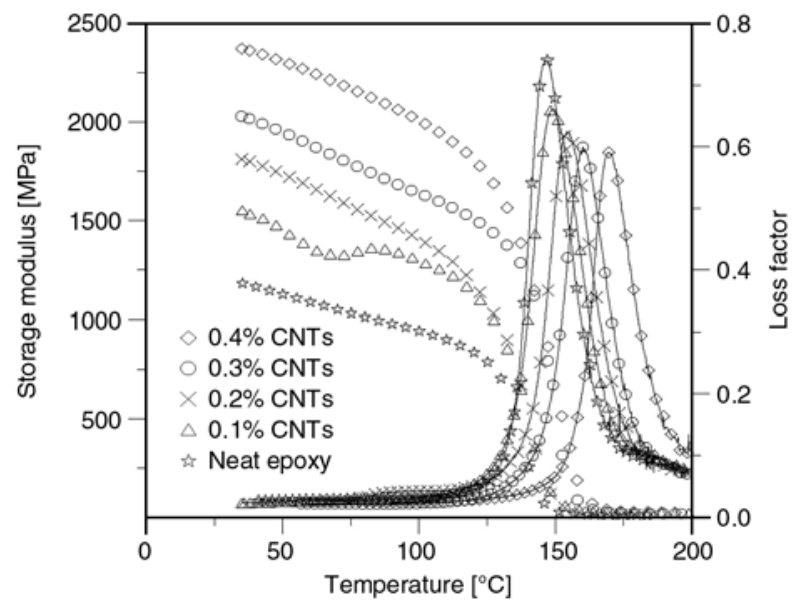

Figure 5. DMA results of neat and nanophased epoxy

tangular bars measuring $2 \mathrm{~mm} \times 30 \mathrm{~mm} \times 12 \mathrm{~mm}$ by a diamond saw.

The loss factor curve, tan $\delta$, of the neat epoxy and its nanocomposites measured by DMA are shown in Figure 5. The peak height of loss factor decreased with higher CNT content, but the temperature determined from the peak position of $\tan \delta, T_{g}$, increased $17^{\circ} \mathrm{C}$. In addition, the width tan $\delta$ increased with higher CNT content. Similar results have been observed in other nanocomposites [21]. Figure 5 also shows the DMA plots of storage modulus vs. temperature as a function of loading carbon nanotubes. The storage modulus steadily increased with higher CNT weight percents. The addition of $0.4 \mathrm{wt} \%$ of carbon nanotube yielded a $93 \%$ increase of the storage modulus at $30^{\circ} \mathrm{C}$. The high aspect ratio and elastic modulus of CNTs, as compared to nanoclay and nanoparticles [7, 8], increase the storage modulus with smaller amounts of CNTs.

Thermogravimetric Analysis (TGA) was conducted with a TA Instruments TGA2950 in nitrogen gas at a heat rate of $10^{\circ} \mathrm{C} / \mathrm{min}$, from ambient to $600^{\circ} \mathrm{C}$. The TGA samples were cut into small pieces using an ISOMET Cutter and were machined using a mechanical grinder to maintain sample weights between 5-20 mg. Universal Analysis 2000-TA Instruments Inc., a data acquisition system, generated the real-time characteristic curves. All TGA tests are run in nitrogen gas. Figure 6 shows the TGA results of neat and nanophased epoxy. The normalized weights vs. temperature curves of five materials overlap. All samples started to decompose around $340^{\circ} \mathrm{C}$ and completely decomposed around $460^{\circ} \mathrm{C}$. The derivative peaks of weight vs. temperature curves show the decomposition tem-

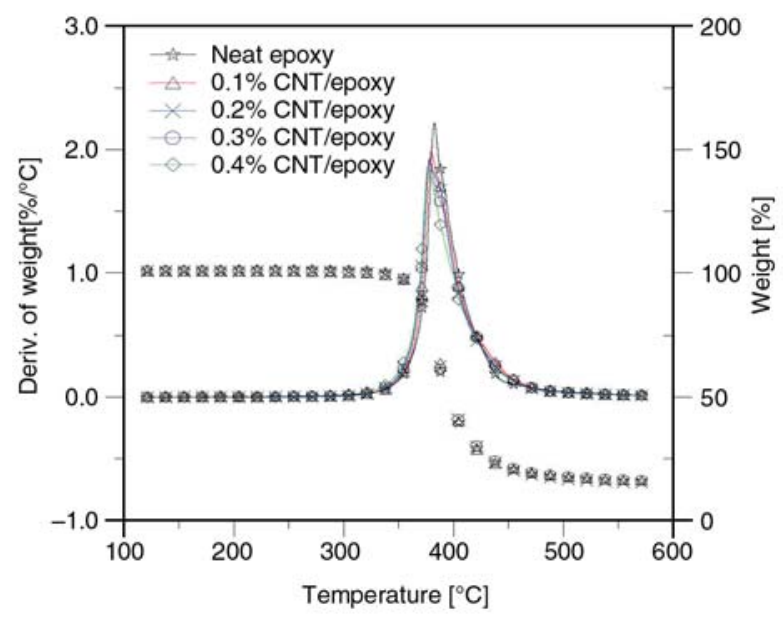

Figure 6. Normalized weight vs. temperature curves of neat and nanophased epoxy

perature. But CNT has little effect on decomposition temperature of epoxy.

\subsection{Mechanical response}

Flexural tests were performed according to ASTM D790-86 under a three-point bend configuration. The tests were conducted in a $10 \mathrm{kN}$ servo-hydraulic testing machine equipped with a Test Ware data acquisition system. The machine was run under displacement control mode at a crosshead speed of $2.0 \mathrm{~mm} / \mathrm{min}$. All the tests were performed at room temperature. Test samples were cut from the panels using a Felker saw fitted with a diamond coated steel blade. Five replicate specimens from four different materials were prepared for static flexure tests.

Typical stress-strain behavior from the flexural tests is shown in Figure 7. All specimens failed immediately after the tensile stress reached the maximum value. The stress-strain curves showed considerable non-linearity before reaching the maximum stress, but no obvious yield point was found in the curves. Five specimens were tested for each condition; the average properties obtained from these tests are listed in Table 1.

Table 1. Mechanical properties of neat and nanophased epoxy

\begin{tabular}{|c|c|c|c|}
\hline & $\begin{array}{c}\text { Modulus } \\
{[\mathbf{G P a}]}\end{array}$ & $\begin{array}{c}\text { Strength } \\
{[\mathbf{M P a}]}\end{array}$ & $\begin{array}{c}\text { Failure strain } \\
{[\%]}\end{array}$ \\
\hline Neat epoxy & 2.46 & 93.5 & 4.02 \\
\hline $0.1 \%$ CNT & 2.54 & 109 & 6.06 \\
\hline $0.2 \%$ CNT & 2.60 & 115 & 6.80 \\
\hline $0.3 \%$ CNT & 2.65 & 121 & 7.58 \\
\hline $0.4 \%$ CNT & 2.75 & 113 & 5.12 \\
\hline
\end{tabular}




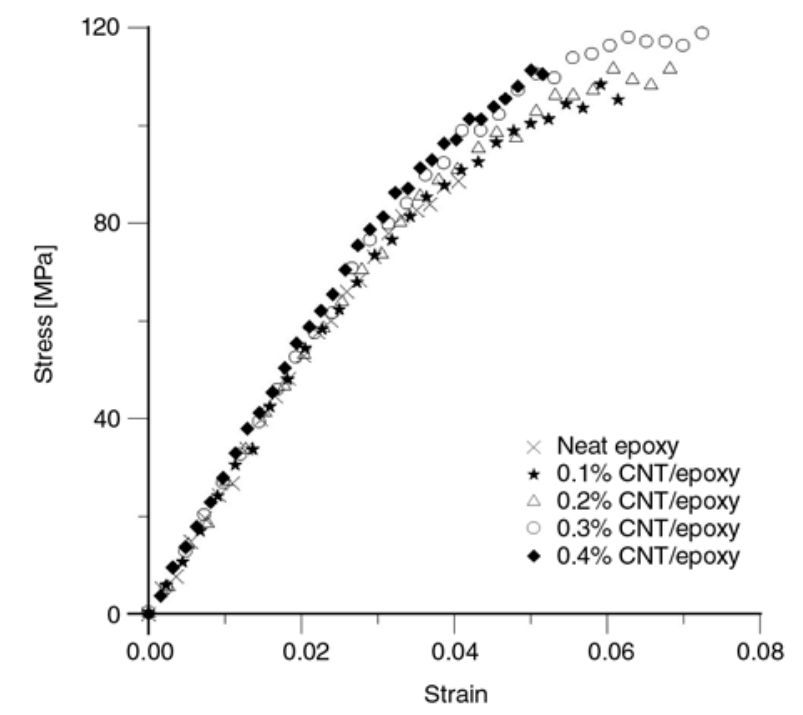

Figure 7. Stress strain curves of epoxy and CNT/epoxy

The modulus of the nanophased epoxy increases continuously with higher CNT content (Table 1 , Figure 7). The tensile modulus improved by $11.7 \%$ with an addition of $0.4 \mathrm{wt} \%$ of CNTs. However, the system with $0.3 \mathrm{wt} \%$ infusion is the best, with a $28.3 \%$ strength enhancement (Table 1, Figure 7). The strength begins to decrease with $0.4 \mathrm{wt} \%$ loading, although the gain in modulus is maintained. See Figure 8 for the relationship between modulus, strength, and CNT weight fraction. The dispersion of CNTs that restricts the mobility of polymer chains under loading improved the modulus and strength in small loadings. The high aspect ratio, high modulus, strength of CNTs also contributed to the reinforcement. However, the decrease of strength with high CNT content can be attributed to

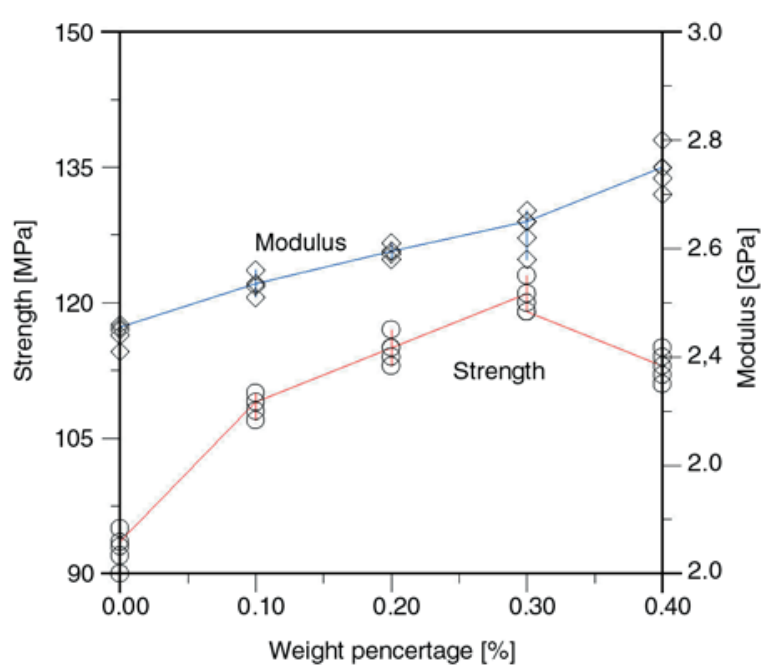

Figure 8. Effect of CNT content on strength and modulus of neat and nanophased epoxy following two effects: First, the dispersion of CNTs is not uniform in higher loading systems. Acoustic cavitation is one of the most efficient ways to disperse nanoparticles with small loading into the pure materials. Previous results have also indicated that, using the acoustic cavitation method, the optimal loading of carbon nanofibers in epoxy is $2.0 \mathrm{wt} \%$ [7] and the optimal loading of $\mathrm{SiC}$ nanoparticles in epoxy is $1.0 \mathrm{wt} \%$ [6]. The other one, voids may have also decreased the strength. Choi and Gojny reported that few voids were produced during the fabrication process and that voids increased with the higher nanoparticle contents $[25,26]$.

Fracture toughness of neat and nanophased epoxy was determined from static three-point tests of the single edge notch specimens. Each of these specimens was cycled 100 times between 4 and $40 \%$ of the peak load at $1 \mathrm{~Hz}$ and then statically tested. During the static tests, the change in specimen length $\Delta l$ was measured by recording the ram positions through the displacement transducer of the MTS machine.

The critical stress intensity factor, $K_{I c}$, was calculated according to the Equations (5) and (6):

$K_{I c}=\left(\frac{P}{B} w^{3 / 2}\right) f(a / w)$

where $P$ - applied load on the specimen, $B$ - specimen thickness, $w$ - specimen width, $a$ - crack length, and

$$
\begin{aligned}
& f(a / w)= \\
& \frac{3 \sqrt{\frac{a}{w}\left[1.99-\left(\frac{a}{w}\right)\left(1-\frac{a}{w}\right)\left(2.15-3.93 \frac{a}{w}+2.7 \frac{a^{2}}{w^{2}}\right)\right]}}{2\left(1+2 \frac{a}{w}\right)\left(1-\frac{a}{w}\right)}
\end{aligned}
$$

Figure 9 shows the load-displacement diagrams of neat epoxy and of $0.3 \mathrm{wt} \%$ CNT/epoxy. Since nonlinearity was seldom observed in load-displacement diagrams, the critical stress intensity factor $\left(K_{I c}\right)$ of materials was calculated from the peak load of each load-displacement curve, and was plotted as a function of the CNT weight fraction (Figure 10). It shows that enhancement reaches a maximum for the critical stress intensity factor at 


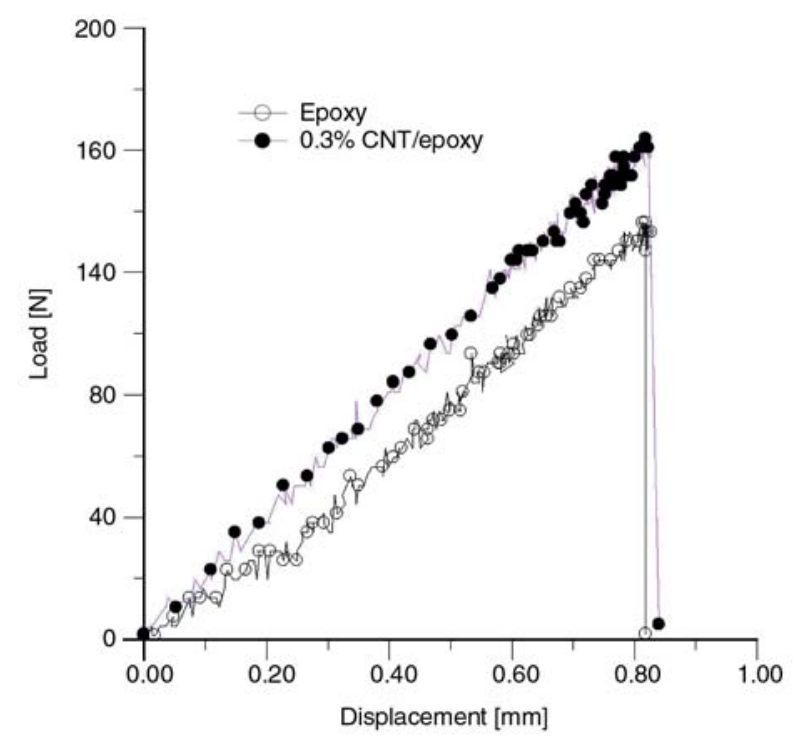

Figure 9. Load-displacement curves in fracture test

$0.3 \mathrm{wt} \%$. Degradation in fracture toughness was found in $0.4 \%$ system.

\subsection{Fracture surface}

The fracture surfaces of composites give first information about failure mechanism and influence of CNT on failure process. SEM-images were taken with a Jeol 2001 at acceleration voltages $25 \mathrm{kV}$ on the fracture surfaces of the neat epoxy and its nanocomposites. The initial crack occurred at the tension edge of both the neat and nanophased specimens (Figures 11a and 11b). Neat epoxy resin

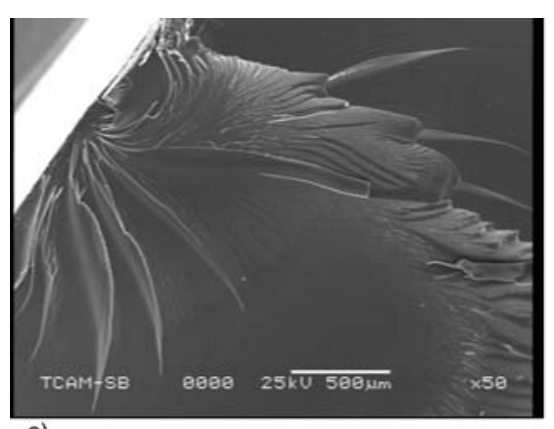

a)

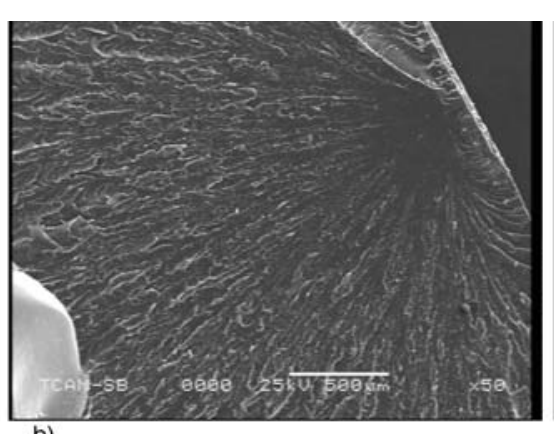

b)

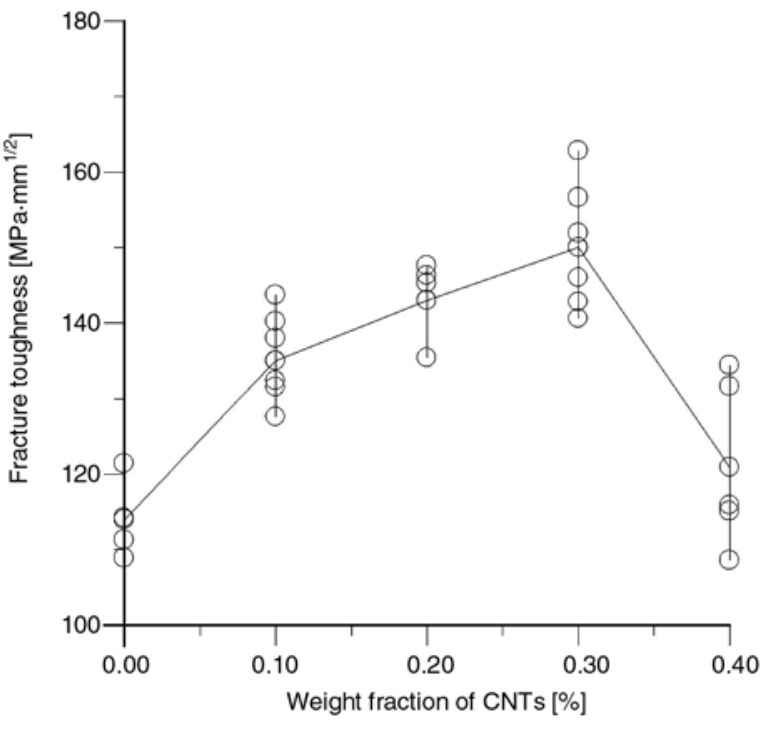

Figure 10. Effect of CNT contents on fracture toughness of epoxy

exhibits a relatively smooth fracture surface and the higher magnification SEM picture in Figure 11c indicates a typical fractography feature of brittle fracture behavior, thus accounting for the low fracture toughness of the unfilled epoxy. The distance between two cleavage steps is range from 40$100 \mu \mathrm{m}$ and the cleavage plane between them is flat and featureless. Smooth fracture surface in neat epoxy revealed that crack propagated through specimen along the same plane. The fracture surfaces of the nanocomposites show considerably different

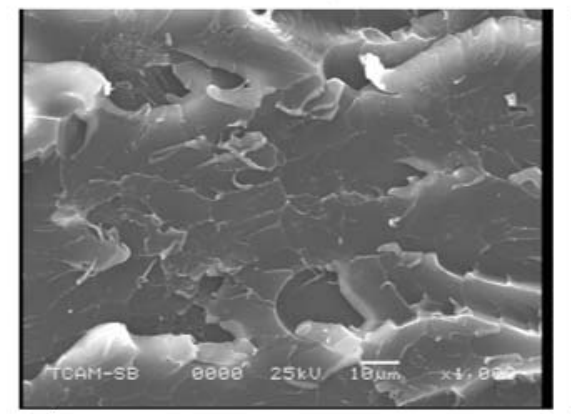

e)

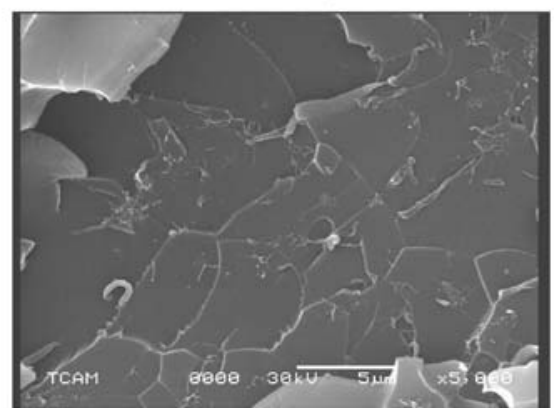

f)

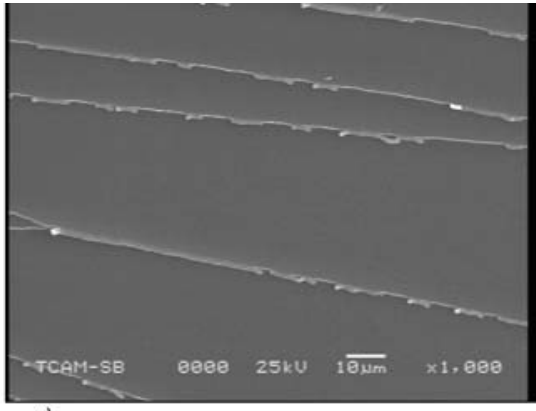

c)

Figure 11. Fracture surface of nanophased epoxy 


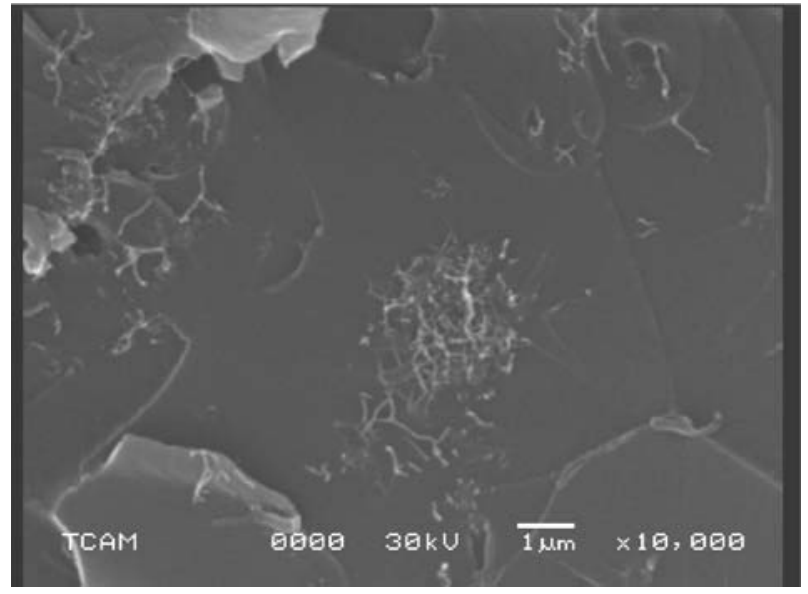

Figure 12. Fracture surface of $0.4 \%$ CNT/epoxy

fractographic features. For example, the failure surfaces of the nanocomposite are rougher with the CNTs added into the epoxy matrix (Figures $11 \mathrm{~b}$ and 11d). The higher magnification SEM picture in Figure 11e shows that the size of the cleavage plane decreased to $10 \mu \mathrm{m}$ after the infusion of the CNTs. The decreased cleavage plane and the increased surface roughness imply that the path of the crack tip is distorted because of the carbon nanotubes, making crack propagation more difficult. Figure 11d also shows that CNTs were uniformly dispersed in the epoxy. The flat cleavage planes were formed by the network of cleavage steps and each plane contains at least one carbon nanotube. During the failure process, the crack propagation changed direction as it crossed CNTs. The bridge effect, which prevents crack opening, increased strength in the CNT/epoxy matrix.

When the CNT content increased to $0.4 \mathrm{wt} \%$, a large particle, an agglomeration of several carbon nanotubes (Figure 12), was observed in the fracture surface. At a low stress level, the agglomerated particle increased the stiffness of the material, but at a high stress level, the stress concentration caused by the agglomerated particle initiated a crack, which made the sample fail quickly.

\section{Conclusions}

Multi-walled carbon nanotubes have been infused in epoxy by ultrasonic method. Based on electrical, thermal and mechanical experiment results, we reached the following conclusions.

1. Ultrasonic cavitation is an efficient method of infusing carbon nanotubes into epoxy resin when CNT weight fractions are lower than $0.3 \mathrm{wt} \%$. Above the $0.3 \mathrm{wt} \%$, CNTs agglomerated.

2. The frequency dependent behavior of CNT/ epoxy can be described by using as a $R$ - $C$ circuit model. The resistivity of epoxy decreased with CNT content, and permittivity increased with increasing of CNT.

3. Compared to neat epoxy, DMA results indicated a $93 \%$ improvement in storage modulus in $0.4 \mathrm{wt} \% \mathrm{CNT} / \mathrm{epoxy}$ at room temperature and a $17^{\circ} \mathrm{C}$ increase in $T_{g}$. However, the decomposition temperature decreased with higher CNT contents.

4. Flexural modulus steadily increases with a higher CNT weight percent. Modulus improved by $11.7 \%$ with an addition of a $0.4 \mathrm{wt} \%$ of CNTs. Flexural strength and fracture toughness peaked in a $0.3 \mathrm{wt} \% \mathrm{CNT/epoxy} \mathrm{system.} \mathrm{The}$ decrease in strength and fracture toughness in $0.4 \%$ CNT/epoxy was attributed to poor dispersions of nanotubes in the composite.

\section{Acknowledgements}

The authors would like to gratefully acknowledge the support of the Air Force Minority Leaders Nanocomposites Research and Education Program and National Science Fundation.

\section{References}

[1] Imanaka M., Nakamura Y., Nishimura A., Iida T.: Fracture toughness of rubber-modified epoxy adhesives: Effect of plastic deformability of the matrix phase. Composites Science and Technology, 63, 4151 (2003).

[2] Chikhi N., Fellahi S., Bakar M.: Modification of epoxy resin using reactive liquid (ATBN) rubber. European Polymer Journal, 38, 251-264 (2002).

[3] Xian G., Walter R., Haupert F.: Friction and wear of epoxy/ $\mathrm{TiO}_{2}$ nanocomposites: Influence of additional short carbon fibers, Aramid and PTFE particles. Composites Science and Technology, 66, 3199-3209 (2006).

[4] Vasconcelos P. V., Lino F. J., Magalhaes A., Neto R. J. L.: Impact fracture study of epoxy-based composites with aluminium particles and milled fibres. Journal of Materials Processing Technology, 170, 277283 (2005). 
[5] Xian G. J., Walter R., Haupert F.: Friction and wear of epoxy/ $/ \mathrm{TiO}_{2}$ nanocomposites: Influence of additional short carbon fibers, aramid and PTFE particles. Composites Science and Technology, 66, 3199-3209 (2006).

[6] Rodgers R. M., Mahfuz H., Rangari V. K., Chisholm N., Jeelani S.: Infusion of SiC nanoparticles into SC15 epoxy: An investigation of thermal and mechanical response. Macromolecular Materials and Engineering, 290, 423-429 (2005).

[7] Zhou Y., Pervin F., Biswas M. A., Rangari V. K., Jeelani S.: Fabrication and characterization of montmorillonite clay-filled SC-15 epoxy. Materials Letters, 60, 869-873 (2006).

[8] Zhou Y., Farhana P., Rangari V. K., Jeelani S.: Fabrication and evaluation of carbon nano fiber filled carbon/epoxy composite. Materials Science and Engineering, Part A: Structural Materials, 426, 221-228 (2006).

[9] Abacha N., Kubouchi M., Tsuda K., Sakai T.: Performance of epoxy-nanocomposite under corrosive environment. Express Polymer Letters, 1, 364-369 (2007).

[10] Du J-H., Bai J., Cheng H-M.: The present status and key problems of carbon nanotube based polymer composites. Express Polymer Letters, 1, 253-273 (2007).

[11] Liao Y-H., Marietta-Tondin O., Liang Z-Y., Zhang C., Wang B.: Investigation of the dispersion process of SWNTs/SC-15 epoxy resin nanocomposites. Materials Science and Engineering, Part A: Structural Materials, 385, 175-181 (2004).

[12] Zhao C., Hu G., Justice R., Schaefer D. W., Zhang S., Yang M., Han C. C.: Synthesis and characterization of multi-walled carbon nanotubes reinforced polyamide 6 via in situ polymerization. Polymer, 46, 5125-5132 (2005).

[13] Kim S., Pechar T. W., Marand E.: Poly(imide siloxane) and carbon nanotube mixed matrix membranes for gas separation. Desalination, 192, 330-339 (2006).

[14] Cai H., Yan F., Xue Q.: Investigation of tribological properties of polyimide/carbon nanotube nanocomposites. Materials Science and Engineering, Part A: Structural Materials, 364, 94-100 (2004).

[15] Ogasawara T., Ishida Y., Ishikawa T., Yokota R.: Characterization of multi-walled carbon nanotube/ phenylethynyl terminated polyimide composites. Composites, Part A: Applied Science and Manufacturing, 35, 67-74 (2004).

[16] Gojny F. H., Wichmann M. H. G., Fiedler B., Schulte K.: Influence of different carbon nanotubes on the mechanical properties of epoxy matrix composites-A comparative study. Composites Science and Technology, 65, 2300-2313 (2005).
[17] Koerner H., Liu W., Alexander M., Mirau P., Dowty H., Vaia R. A: Deformation-morphology correlations in electrically conductive carbon nanotube- Thermoplastic polyurethane nanocomposites. Polymer, 46, 4405-4420 (2005).

[18] Kuan H-C., Ma C-C. M., Chang W-P., Yuen S-M., Wu H-H., Lee T-M.: Synthesis, thermal, mechanical and rheological properties of multiwall carbon nanotube/waterborne polyurethane nanocomposite. Composites Science and Technology, 65, 1703-1710 (2005).

[19] Seo M-K., Park S-J.: Electrical resistivity and rheological behaviors of carbon nanotubes-filled polypropylene composites. Chemical Physics Letters, 395, 44 48 (2004).

[20] Li C., Liang T., Lu W., Tang C., Hu X., Cao M., Liang J.: Improving the antistatic ability of polypropylene fibers by inner antistatic agent filled with carbon nanotubes. Composites Science and Technology, 64, 2089-2096 (2004).

[21] Seo M. K., Lee J. R., Park S. J.: Crystallization kinetics and interfacial behaviors of polypropylene composites reinforced with multi-walled carbon nanotubes. Materials Science and Engineering: A, 404, 7984 (2005).

[22] Reynaud E., Gauthier C. Perez J.: Nanophases in polymers. Review Metallurgie, 96, 169-176 (1999).

[23] Gojny F. H., Wichmann M. H. G., Fiedler B., Bauhofer W., Schulte K.: Influence of nano-modification on the mechanical and electrical properties of conventional fibre-reinforced composites. Composites, Part A: Applied Science and Manufacturing, 36, 1525-1535 (2005).

[24] Gojny F. H., Wichmann M. H. G., Fiedler B., Kinloch I. A., Bauhofer W., Windle A. H., Schulte K.: Evaluation and identification of electrical and thermal conduction mechanisms in carbon nanotube/epoxy composites. Polymer, 47, 2036-2045 (2006).

[25] Choi Y-K., Sugimoto K-I., Song S-M., Gotoh Y., Ohkoshi Y., Endo M.: Mechanical and physical properties of epoxy composites reinforced by vapor grown carbon nanofibers. Carbon, 43, 2199-2208 (2005).

[26] Gojny F. H., Schulte K.: Functionalisation effect on the thermo-mechanical behaviour of multi-wall carbon nanotube/epoxy-composites. Composites Science and Technology, 64, 2303-2308 (2004). 